\title{
Biaya Seikhlasnya or Sincere Tariffs in Public Service: Citizen's Responses Towards Vague Corruption Practices
}

\author{
Aris Chandra Pradikta \\ Center for Population and Policy Studies \\ Universitas Gadjah Mada \\ Yogyakarta, Indonesia \\ chandraaris@gmail.com
}

\author{
Burhan Ali \\ Institute of Social and Cultural Anthropology \\ University of Freiburg \\ Breisgau, Germany
}

\begin{abstract}
Corruption in organizational theory has been understood through formal law violation and power abuses frame. However, the proposition in organizational perspectives are gaining criticism as failed in capturing local culture of societies. This research presents cultural sides of corruption in order to grasp with vague practice in the institutional theory. Within the setting of petty corruption in Indonesia, we provide citizen perspectives when they deal with bribery almost in daily basis. Our findings reveal that religious term, especially Ikhlas or sincere, often coined by official to activate philanthropy and citizen's empathy. In turn, it makes citizen to hand money without feeling of being coerced. However, we also found contradiction in the citizen perceptions and actions. On the one hand, they perceived the practice against the law and ethics. On the other hand, they also intend to give, if they are asked unofficial cost in the future. Further, this research also contributes to interaction between organizational theory and cultural in corruption.
\end{abstract}

Keywords - Indonesia, corruption, religion ethics misconduct, culture and corruption, citizen responses.

\section{INTRODUCTION}

Maintaining bureaucracy in order to remain professional, efficient and congruent according to citizen needs is challenging efforts particularly in developing countries. Based on Governance Indicators from World Bank, Indonesia's score is at 54,81 in term of government effectiveness and 34,13 in control of corruption among 230 countries [1]. Whereas, closer to 100 is the highest or having better rank. In contrast, zero is the worst score. Within many problems that the country is facing, this paper remains to focus on corruption as causing serious obstruct in citizens' day to day life and hinder business improvements.

Despite, in fact, problem of corruption also occurs in high income countries, yet the consequences of corruption on developing countries is severe and potentially widening income gap, slowing economic development, as well as worsening economic conditions [2]. In Indonesia, problem such as environmental degradation [3], social capital and trust violation [4], slowing on educational development (Kompas, 20 June
2016), are among the impacts of power abuse which practiced in government institutions.

There are many ways to grasp with the existence of corruption. Among those, structural and economics approaches are popular in previous research. Low wages factor for instance, is seen as push motivation of public personnel to find additional income sources and to justified misused to its authority [15]. In solution, special remuneration ways have been taken to increase personal earning, as has been done by Indonesia's ministry of finance. However, critics also showed that remuneration is not solely a way to make improvement. Moreover, broader scope of structural reform must be taken.

Even though, it has been well developed from organizational point of view, however, lack of understanding within particular culture as well as embedded value, such as religion, later, attract scholars to gain better understanding in using broader scope of cultural. Currently, discussion of the emerging topics of corruption, based on religion perspectives, provide alternative as well as complexities in understanding the situation. Vaduva has narrated, that ethical standard to prevent corruption, should regard the religion point of views where local condition setting of the misbehaved take a place [6]. Thus, the often neglected variable could be explained better within realm of corruption. On the contrary, opponent has seen the fact that it is always contradictory, while high rank of corrupt countries is also having more concern of religion [5].

However, our research is not seeking to extend the debate of either religion affecting individual performance positively or conversely. The reason is that the clear position on religion as a value, as well as any other values, for being perceived as tool. Where men behind the gun are responsible to control what outcomes and consequences of their actions. Instead, our curiosity is sparked in the unique pattern that prevail in particular environment. In which, religious concepts are used in delivering vicious intentions as well as in order to be culturally accepted by society. Likewise, this research also constructed as a respond in understanding situation, where, there is an interaction between cultural and institutional dynamics. 
Sincerity cost or biaya seikhlasnya, in this case, however, is a unique phenomenon that emerge within Indonesia society. As sometimes bribery demand money before the process would have executed and tend to force the target to engage. On the contrary, sincere cost, usually, though in some evidences occurred before, expressed by official when public services have been issued. In addition, this kind of demanding money is flexible that depend on willingness of citizens to give or refute.

Our study tries to reveal how using term of religious' "ikhlas" or sincere, sometimes, blocking the control of citizens as a mean to prevent the corrupt act of officials. This research is important as citizen check and balances are regarded for one of the defending mechanisms to maintain social structure [7] and associate with effort of maintaining trust of formal structures [8]. By take a look at the citizen responses, it is also addressed of how future efforts should be taken in order to prevent personal benefit in principal-agent relations.

\section{LITERATURE REVIEW}

\subsection{Cultural Perspectives on Corruption in Public Services}

The term of corruption, that commonly used, referring to exercise of formal power, to gain personal interest. However, the study on corruption in some perspectives may question of its existences in particular circumstances. In ethnography for instance, corruption is often understood as clash of values that entrench within two different institutions. In a formal structure, on the one hand, paying unofficial money is forbidden as regarded for abusing of power. On the other hand, traditions that stressing on mutual understanding, kinship as well as maintaining ties are deemed to be part of the social interactions [9].

Between two individuals and, or individual with organization relations, exchange gifts are particular ways to express gratitude as someone has benefited others [10], from pass the license to allow business activities engage in market place [11]. In that sense, corruption is vague as both irresponsible personal official motives in seeking of economy interest and as the existence of social norms and value. In addition, within Indonesia contexts, some findings also stressed on cultural and informal network that influenced formal organizational structures. Informal organization often interacts with value and norm that not only potentially support legacy of corruption, but also possibly blurring citizen's insight that have to follow with corrupt organization rules [12].

Recent famous of Indonesia case, that publicly appealed, were from the legislative institution scandals of asking shares. It was also known as "papa minta saham" or father demand for company shares, and asked additional platforms for affiliated company which advocated by top of country's representatives (Kompas, 19/9/2016). Those phenomena were intertwined values that causing explicit public distrust of state agencies. On the one hand, they were seeking of economic benefit for personal gain, and on the other hand for the sake of maintaining good relations, they expressed their unethical interest using cultural terminology which seemed to be morally accepted by their targets [9].

\subsection{The "Term-Usage" in Unofficial Cost of Public Services}

Corruption occurs within service delivery process usually not expressed in clear way. There are several wording that are used to advocate both parties interest. In bribery that takes place during traffic law violation for instance, Indonesian often use the term of "damai" or literally translate to peace [4]. Peace money, in that situation, is used to cut long process of court and the uniform citizen only knows the way that legitimate action can be dealt sole via court. In which, regular process can be finished at least 7 work days. Therefore, citizen perceives the most efficient ways is through bribery.

In bribery process, narrative or persuasive actions are delivered through softened words. The word that is used usually derived to activate philanthropy, empathy, or gratitude of others. Wording or term can be sourced from religious-like that majority understand the meaning of situation and contexts. "Ikhlas" or Sincere, is the religious term that, for particular situation, is used to ask bribery without coercion.

In Islamic perspective, sincere or ikhlas, is deemed as highly moral value. The terminology can be understood as devoted things that not intended in showing good deed to please other but Allah or God. Another word, which probably be the contrary, is riyya' or showoff [16]. As in Islamic ethics, sincere obliges individual to not remember of what have been given to others and not telling everyone.

Other outcome results of sincerity wording in society is also expressed inside Malay culture. Whereas, ikhlas is associated with the charity giving, benefited others, and sometimes as an insisting saying from someone to others in order to accept gifts [13]. In expressions to obtain unofficial amount of money from clients, there are number of public personnel use cultural understanding term for hidden intentions, particularly derived from religion as well. Whilst, in essence, sincerity is seen as pure deed of someone without expecting return, moreover, unofficial money.

For corrupt civil servants, in particular cases, religion "package" has been sold for personal interests. Which in turn, saying the word of sincerity or pure-hearted, implies as handing amount of banknotes, by citizen or individual, for an exchange of service delivery. In some extents, such demand leads to not reporting the case. As if it was the willing of the money giver rather than the official who was asking for it.

\subsection{Citizen's response to ethical vague behavior}

The cultural aspects of corruption, which mainly expressed by anthropologists, not solely explains wrongdoing actions against formal law. Instead, it entails cultural and social values that have been preserving for quite sometimes in the community. In addition, citizens or communities often use their conscience, network ties and empathy rather than formal relations. Thus, instead of protesting for what is going on, for some people, maintaining "traditional or colonial" relations between principal and agent is through "gifts" giving. In democracy setting, citizens are deemed to be the checker of public official's behavior. However, the control mechanism not always occurs as were discussed [7]. As citizens might think the process is something inheritance and cultural matter [4].

In addition, paying bribe is a breakthrough to not following long bureaucratic process as regulated by formal law [17]. In 
Indonesia context, the bureaucratic processes are too frustrating that make the country left behind in term of business competitiveness. Investors often complain for many tables to be handled.

Even though, paying bribe as a choice to escape from frustrating process, there are also critics delivered to address misbehave of officials. In results, citizens tend to perceive the image of public servants less appreciated and lead to long-term social norms destruction [5]. Likewise, corruption also results in acute poverty and outcome in extremism social movement [18].

\section{RESEARCH METHODS}

This research is mainly conducted using qualitative method. Informant were chosen purposively after had received public services in particular departments. We asked university students to whomever had experience with unofficial costs. In depth interview with semi-structured questions were the main mean to gather information.

In sum, with total 6 informants revealed their experience when asked for being "sincere" and giving tips to officials. In addition, one of our informant also recorded the conversation during the process. Data that obtained in this research then processed and interpreted using existing concept of perceptions toward corruption. Unfortunately, we are unable to gain information from public officials. First it is due to hard to obtain confession as lack of evidences. Unless, one of our informant that recorded their conversation. From the conversation, official confessed how much money usually given by citizen to help the process.

Likewise, we also use observation participatory, with accompanying one of our informants to report his case to local authority. There were 3 institutions, in which our informants been handled in his case. There were newly formed institution for eradicate unofficial cost, it is called "Saber Pungli", then, local police office and Ombudsman representative. However, only one official responded to the report.

\section{RESULTS}

Based on our informant's experience, mainly, the service that they were dealing with, are such as citizenry administration, including letter of statement from official or personal identity card. Despite corruption practices widely accepted, in our finding, complexities exist when our informant following rules in so-called bribery game. However, they also felt in public trust violation and worsening perception upon officials.

\section{A. Citizen's Perception of Unofficial Cost}

Problem of Indonesia civil servants' ethic is deemed as deteriorating factors that slowing economic growth of the country. Special team recently has formed to eradicate unofficial cost (pungutan liar or commonly abbreviated as "pungli") which practiced commonly by state officials. A day after its formed, police raided building of ministry of transportation in Jakarta and found more than one billion rupiahs of money paid for many interests (Kompas, 12 October 2016).

In smaller cases, our research found unofficial cost often expressed within cultural terms. The stories of our respondents have implied that they were once asked to give money as amount as they willing to give. Despite they had chances to refuse, mainly handled money is common as they felt the amount within reasonable range, empathy toward low-paid officials and avoiding conflict.

In results, perception of citizens toward ethical violation of officials was varying among six of our respondents. However, generally they feel the behavior was unacceptable and could violating citizen's trust upon formal system.

R1: They are paid by government to do the job, but still
asking additional money for service that they are paid for.

R2: Mainly, I have no problem as the amount of money I had given were not much, but for some people from low income society for instance, perhaps it was something. Since the services related with basic of citizen needs, such as residence card, legalized copy of official documents or family member card. Received services are rights of all society. Central government should pay more attention and control service delivery in local government.

R3: Shame on them, it was so shame, it was not personal who asking for money, but near the desk there was a box, please put something as you are willing to give, he said.

In Islamic value, giving donation is asserted as to help the religion running its activities. The value of giving for charity is done with sincere or pure-hearted. When officials asked tips using "ikhlas" or willingness from citizen to give, all of our respondents passed them money. Even though, they felt that it was not right as well.

Compared to Malay culture that expressing sincerity to insist or convince the object to accept [13], our finding showed reversely. However, similarity is still associated with the context of charity giving that both culture share value of languages to understand meaning each other. In addition, their answers reveal that how citizen perceive of public official background affect how their willingness to engage in bribery games. While other research concern that social context of corruption will lead to non-corrupt perceptive as it is accepted as social norms [9]. Our finding complement the understanding to what extent citizen willing to engage using empathy.

Within context of corruption in public services, officials tried to seek individual economic interest through the using of social understandable expression, which is sincerity. Therefore, for our respondents, the word implies the need to pass certain money based on ability and willingness to pay. 
Usually range from 2,000 to 20,000 rupiahs depend on each citizen.

Special case occurred from one of our informant that was asked for money up to 4 million rupiahs during the process of issuing inheritance certificate. Based on the ministry of homeland decree, the cost provision is mandated to every region. However, official cost is not charged for the region which our informant resides, or in other words it supposed to be free. Fortunately, our informant has the recording of the process and he willing to share for the research purpose.

R4: At the time I went to head of political leader in my village, he could not give the exact number of the cost. He said tomorrow I will call you how much it cost, he said. The next day my phone rang, I was informed that the cost of inheritance certificate is based on percentage from total family wealth who passed away. I shocked to hear that. At the end, I jugged the price. It costs me up to 4 million (Rupiahs). He said, if you are sincere (ikhlas) to give me that amount of money, I have no problem to issue your certificate. At the end, I just wondering, how this corrupt politician could be elected.

From several answers of informant, mostly they become aware that the public service delivery in their region were not free from corruption. However, various perceptions emerge such as empathy, distrust, and forgiving the behavior. For empathy and forgiving perceptions, in essence, they tried to understand that probably the income of public servants is not enough to support their family needs. In addition, forgiveness is associated with their acceptance of small amount money that were asked.

Experimental research has been conducted to understand how corrupt behavior affecting social structure and potentially imitated by others as people perceived that informal process could fulfill their needs with official [8]. In this case, the distrust perception among our informants, however, would not lead to stop the action for handing notes in the future. In addition, they assert in willingness to give, if, later, civil servants asked them for unofficial money.

To compare, in another research, trust toward government can also be expressed through the control of citizen engagement against unethical behavior [14]. Which, in this research, we cannot show that unwillingness to control due to lack of trust. However, there are several adjustment factors that affecting such decision. That first, our respondent relied to formal mechanism. In addition, confrontation means possibly fail in the process in issuing needed formal documents.

\section{B. The Responses of Citizen}

We found contradictions results of our informants, on the one hand, they understand asking money using ikhlas term was not right and act as authority violation. On the other hand, they still willing to give the money and sometimes, had delivered gratitude as official helped them. These due to several factors that become main concern, such as the perception of citizen that could not escape in bribery game [8] and trying to avoid conflict.

In bribery game, official roles as an actor who has the authority to pass or not to pass particular legal document such as business permit or any permissions for granting rights of the holders. If citizen willing to engage and provide amount of money that they were asked, later they will get documents that they need [8]. Conversely, if they are not willing to engage, the punishment that they received is not getting what they wanted or should follow long bureaucratic process or getting social sanction. As expressed by our informants as follows

\section{R3: If I were not giving money, they served me like I was} not there.

\section{R2: I was afraid that they would not issue my document.}

R4: I needed that document, and I did not have time to follow such a long process, in which, it could be simple, but they made it difficult. When they offered me to help in the process, that was the time we agreed about the money. I don't think that working people could make it in a day process. Approximately it took 2 weeks in issuing with intense meeting and required mobile within working hour.

For response to the request of unofficial cost using religion terms, our informant expressed their view regarding this phenomenon. The question was, do you agree or disagree that religion is important for self-control in avoiding indecent behavior. Mainly, they believe that religion having positive outcome with behavior if practiced in correct ways. Therefore, religion could not be blamed for such a violating ethics output. Furthermore, one perception emerged as perceived the true believer will not use the religion for individual seeking economic benefit. However, one of our informants voiced that it does not associate as the primary concern to control corrupt is the present of vertical state control.

Beside economic approach, other argument for understanding how our informant voluntarily involved in bribery mechanism was trying to avoid conflict. Speak up or confronting argument in Indonesia culture usually regard as disrespect and disrupt public order. Moreover, if subjects face to face with more senior official and the amount of money is still reasonable, giving up money and forgiving the act were deemed as the best way to go through the process. Whereas, exchange gifts are common to express gratitude for someone, in this case is official, that has benefited others or civilians [10].

\section{Dealing Corruption Case via Formal Institutions}

In this research, we also accompanied one of the respondents to report his case in local institutions. First, he had suspicion of local political leader acts when dealing to issue on his certificate. Second, he has evidence of recorded conversation during the process. Third, the money that were asked by the official are too many for him and he also asked us 
to accompanied the process. Other reason also we wanted to test the whistle blower system in Indonesia.

We had reported in three formal institutions, that are Local Police Office, Saberpungli website and Ombudsman. Based on three institutions, we found that Ombudsman is the fastest to response toward our report. In ombudsman, the finishing process of the incoming report are varied that based on citizen decision. The options that given were reporting the case to supervisor or return the money. Later, our respondent chose to returning money that were handed.

During two-week process, the officer who were asking unofficial cost were summoned by Ombudsman and admitted for what he has done. Later, in closing the case both parties are invited to attend meeting and sign paper as the case are formally closed. We also found from the meeting, that village political leader as the suspect, accused our respondent to put him down in the local politics contestation.

In addition, from the suspect point of views we found several perceptions of old-minded or feudal ways in exploiting citizen and treat them as subordinate in society. The facts were revealed through informal conversation after the meeting. The elected-officer who asked bribery told that our informant should have not reported as it was part of the customs in society. He meant that handed money is a way to deliver gratitude for official in helping the process of public services

\section{The Citizen Expectations of Future Services}

Based on discussion with our informants, generally, they expect for the clarity of time and simplification of process. In addition, they agree that unofficial cost should not be repeated in the future. We also receive, the complain of regulation that make local discretion existed. For instance, it was the case of issuing certificate of inheritance. There are several critics delivered by our informant regarding its process and function as well.

The process of issuing the certificate for instance, citizen is obliged signing paper with two additional witnesses, which is their neighbors. Problem emerged as witnesses the person who are. In addition, for the certificate function, it has to be for single purpose only. If their parents or person who passing the wealth to whomever has right to receive has wealth, such as car, land, bank savings or house, the certificate can be used only for one of them. Additional process is required as many as number of the wealth. Very often, transactional dealing occurs during this process and regulation made in very loose as well as not transparent, which enabling negative discretion appear.

\section{CONCLUSION}

This research tries to explain how petty corruption occur in society and how citizen response when facing such situations. The particular term used in this research is sincerity or ikhlas which based on Islamic ethics of individual for willingness in giving charity. Our research findings show main excuses of citizens for had passed banknotes during the process in service deliveries were afraid of official not issuing their license, or issuing but with longer process, relatively small amount of money, and perceive unfriendly or unrespect treatment when not giving tips. Even though, informants in our research willing to engage in bribery game, they expressed distrust in public officials, which in turn, they perceive that public service are slow, unprofessional, corrupt, and lack of service orientation.

In addition, our informant expect that future service delivery need to be improved in area such as clarity of process, simplified procedure and technology involvement, which might help to lessen the face to face interaction that potentially as the dominant ways for corruption occurred. In addition, we also acknowledge the effect of "term" usage in affecting citizen engagement in such bribery game. Thus, we also suggest, more expansive research need to be carried out as gain better understanding of culture and corruption. Current research might have helped particular areas, such as organizational settings, either formal or informal; the cultural of corruption, however, citizen empowerment is also deemed as important factors to prevent corruption from the demanded side.

\section{REFERENCES}

[1] The Worldwide Governance Indicators 2015 by World Bank, downloaded from http://data.worldbank.org/data-catalog/worldwidegovernance-indicators

[2] A. Soans and M. Abe, 2016, "Bribery, Corruption and Bureaucratic Hassle: Evidence from Myanmar", in Journal of Asian Economics, vol. 44, pp. 41-56. April 2016

[3] C. Koyunen and R. Yilmaz, 2009, "The Impact of Corruption on Deforestation: A Cross-Country Evidence", vol.42, pp.213-222, Spring 2009

[4] J. W. Buttle, S. G. Davies and A. E. Meliala, 2016, "A Cultural Constraints Theory of Police Corruption: Understanding the Persistence of Police Corruption in Contemporary Indonesia", in Australian \& New Zealand Journal of Criminology, vol.49, pp. 437-454, September 2016

[5] H. Marquette, 2012, "Finding God' or 'Moral Disengagement' in the Fight Against Corruption in Developing Countries? Evidence from India and Nigeria", Public Admin. Dev., vol.32, pp. 11-26, January 2012

[6] S. Vaduva, 2016, "From Corruption to Modernity The Evolution of Romania's Entrepreneurship Culture", Switzerland: Springer International Publishing

[7] E. I. Ani, 2015, "Combatting Corruption with Public Deliberation", in South African Journal of Philosophy, vol. 34, pp. 13-28, March 2015

[8] R. Banerjee, 2016, "Corruption, Norm Violation and Decay in Social Capital", in Journal of Public Economics, vol. 137, pp. 14-27, April 2016.

[9] S. Rose-Ackerman, 2010, "Corruption: Greed, Culture, and the State", The Yale Law Journal Online, vol. 120, pp. 125-140

[10] M. Granovetter, 2004, "The Social Construction of Corruption", Conference Paper in "The Norms, Beliefs and Institutions of 21st Century Capitalism: Celebrating the 100th Anniversary of Max Weber's The Protestant Ethic and the Spirit of Capitalism", October 8-9th, 2004, at Cornell University

[11] C. Ahlin, P. Bose, 2007, "Bribery, Inefficiency, and Bureaucratic Delay", in Journal of Development Economics, vol. 84, pp. 465-486, September 2007

[12] M. Ganie-Rochman and R. Achwan, 2016, "Corruption in Indonesia's Emerging Democracy", in Journal of Developing Societies, vol. 32, 159-177, September 2016

[13] C. Goddard, 2001, "Sabar, ikhlas, setia - patient, sincere, loyal? Contrastive semantics of some 'virtues' in Malay and English", Journal of Pragmatics, vol. 33. pp. 653-681, May 2001 
[14] M.Soot and K. Rootalu, 2012, "Institutional Trust and Opinions of Corruption", in Public Admin. Dev., vol. 32, pp. 82-95, January 2012

[15] McLeod, Ross, H., 2008, Inadequate budgets and salaries as instruments for institutionalizing public sector corruption in Indonesia, South East Asia Research, vol. 16, 2: pp. 199-223, July 2008
[16] Lambarra, Fatima and Riener, Gerhard, 2015, On the norms of Charitable Giving in Islam: Two Field Experiments in Morocco, Journal of Economic Behavior \& Organization (Accepted Manuscript)

[17] Torsello, Davide and Venard, Bertrand, 2015, The Anthropology of Corruption, Journal of Management Inquiry, vol. 25, 1: pp. 34-54, January 2016 